\title{
Research on the Application of Virtual Reality Technology in Primary School Science Class
}

\author{
He Yuting, Zhao Jiaojiao \\ College of Chemistry and Chemical Engineering, Zhengzhou Normal University, Zhengzhou, \\ 450044, China
}

Keywords: Virtual reality technology; Primary school science

Abstract: In the context of "Internet + Education", virtual and augmented reality technologies are being integrated with science education in primary schools. Based on the analysis of the background of the times and the existing problems in primary school science education, this paper analyzes the integration application of Virtual Reality education software in primary school science teaching, and analyzes the specific lessons and the advantages of integration.

\section{Introduction}

\subsection{Development requirements of the times}

In the rapid development of the 21st century, information flow, knowledge explosion, modern science and technology is also changing. Some new technologies are penetrating into all aspects of social life with an irresistible trend, and many new forces have been injected into the field of education. Under the background of "Internet plus education", Virtual reality, Augmented reality and Mixed reality are being integrated into education and teaching. The use of technology to change traditional teaching methods and methods is more conducive to students' understanding, mastery and application of knowledge, which is more in line with the requirements of the development of the times. Moreover, when looking forward to the development of important emerging core technologies in 2020, some people have listed Virtual reality and Augmented reality technology into the eight important emerging core technologies. It can also be seen that the development of Virtual Reality and Augmented Reality technology is the trend and requirement of the times.

\subsection{The importance of science education in primary schools}

Science and technology are not only closely linked with national economic development, but also affect all aspects of social development. To develop science and technology and improve people's scientific literacy, the root is to develop education and cultivate high-quality scientific and technological talents. Primary school science education is the most essential root. If we want to do a good job in science and technology, we must start with children and science education in primary schools. In recent years, with the rapid development of international science and technology, China has paid more and more attention to science education. In 2017, China published a new version of 
the compulsory education primary school science curriculum standard, which makes corresponding improvements on training objectives, curriculum nature, basic concepts, design ideas and curriculum objectives, so as to meet the requirements of the new era for students ${ }^{[1]}$. In the primary stage of compulsory education, science subjects are added to the first grade and taken as a basic course. Therefore, it is not difficult to see that the implementation of science education in primary schools is very necessary, and its important position is beyond doubt.

\section{Problems in science teaching in primary schools}

\subsection{Insufficient awareness of importance}

Although science has been popularized in the whole stage of primary education, few schools can fully carry out science. Due to the shortage of teachers in science education major in most schools, many science teachers are part-time, lack of professional knowledge and professional quality, and lack of understanding of the importance of science teaching, so it is not perfect to cultivate students' scientific quality. In addition, under the influence of the concept of exam oriented education, in order to pursue the so-called enrollment rate, teachers mainly teach in the form of explanation, only pay attention to the mastery of scientific knowledge, but ignore the cultivation of students' scientific inquiry ability, practical ability and scientific attitude. At present, most of China's understanding of the importance of science education is still superficial, without in-depth understanding of the importance of science teaching, and even some primary schools in rural areas are in the state of not offering science courses or not implementing science courses.

\subsection{Insufficient conditions of hardware and software equipment}

Primary school science teaching needs certain teaching places and corresponding teaching equipment, which costs more. In order to better meet the needs of primary school science teaching, the state has set up a special subsidy system, in addition to the normal funds in primary school science education, there are additional funds for Science Education ${ }^{[2]}$. This can ensure that schools have the most basic teaching facilities, but now there are not many schools with science laboratories in primary school teaching, and there are few schools equipped with advanced equipment such as Virtual reality and Augmented reality. Moreover, electronic resources and paper science books are not enough. Due to the lack of various hardware and software equipment conditions, the scientific teaching can not be carried out smoothly, which leads to the unsatisfactory teaching effect.

\subsection{Insufficient integration and development of teaching resources}

Some science teachers are only limited to textbooks and teaching reference. At present, with the rapid development of science and technology and information and the rapid change of knowledge, all kinds of teaching resources need to be integrated to achieve better teaching effect. Although many enterprises develop resources related to virtual and augmented reality, they mainly focus on games and entertainment, but few of them integrate virtual and augmented reality technology with teaching resources. Some teachers also pay attention to the integration of teaching resources and students' immersion learning, but most of them just change the surface of the teaching form, while the in-depth integration and improvement of teaching content are often ignored. 


\section{Related concepts}

\subsection{Virtual reality (VR) technology}

Virtual reality (VR) is an immersive interactive environment based on multimedia computer technology, simulation technology and sensor technology ${ }^{[3]}$. Virtual reality (VR) technology is the use of computer related technology to generate a virtual three-dimensional environment that integrates vision, hearing, touch and other senses. It makes users feel immersed in the virtual environment and interact with the objects in the virtual environment, so as to produce the experience and feeling as if they were in the real environment. Virtual reality (VR) technology has four characteristics: interactivity, immersion, multi-perception and imagination.

\subsection{Augmented reality (AR) technology}

Augmented reality (AR) is based on the real situation, which superimposes the virtual objects generated by the computer and adds them to the real environment that users can see directly to realize the interaction between virtual objects and real objects. It includes three basic attributes: the combination of real objects in the real world and virtual objects in the virtual world, the real-time operation in an interactive way, and the integration of real objects and virtual objects in three-dimensional space ${ }^{[4]}$. Augmented reality (AR) technology has the characteristics of real-time interaction, immersion, visualization and the combination of virtual and real. It is a more practical technology and an extension of Virtual reality (VR) technology.

\subsection{Mixed reality (MR) technology}

Mixed reality (MR) technology is to present the virtual objects of the virtual world in the real world, build a bridge of information interaction between users and the virtual world, the real world, so that users can get more real experience. This technology skillfully combines the advantages of VR technology and AR technology, so that AR technology can be better reflected. There are also differences between MR and AR. Mixed reality (MR) technology enables people to see the reality invisible to naked eyes through cameras, while Augmented reality (AR) technology only superimposes virtual objects but ignores the reality itself. At present, Mixed reality (MR) has no mature hardware facilities to market, and software application is only in the theoretical stage, but it has a great prospect in the future.

\subsection{The relationship among VR, AR and MR}

According to the "Reality-Virtual continuum" proposed by Paul Milgram and Fumio Kishino in 1994, the environment presented by the combination of virtual objects and real environment can be classified ${ }^{[5]}$, as shown in Figure 1. It is considered that the real environment and the virtual environment are at two ends respectively, the one close to the virtual environment is Virtual reality (VR), the one close to the real environment is Augmented reality (AR), and the part of hybrid virtual reality (VR) and augmented reality (AR) is Mixed reality (MR). The differences are: VR is to restore the truth, infinitely close to the truth, but the reality is all false; AR is half true and half false, and the true and false complement each other; MR is to confuse the true with the false, which makes it difficult to distinguish the true from the false. 


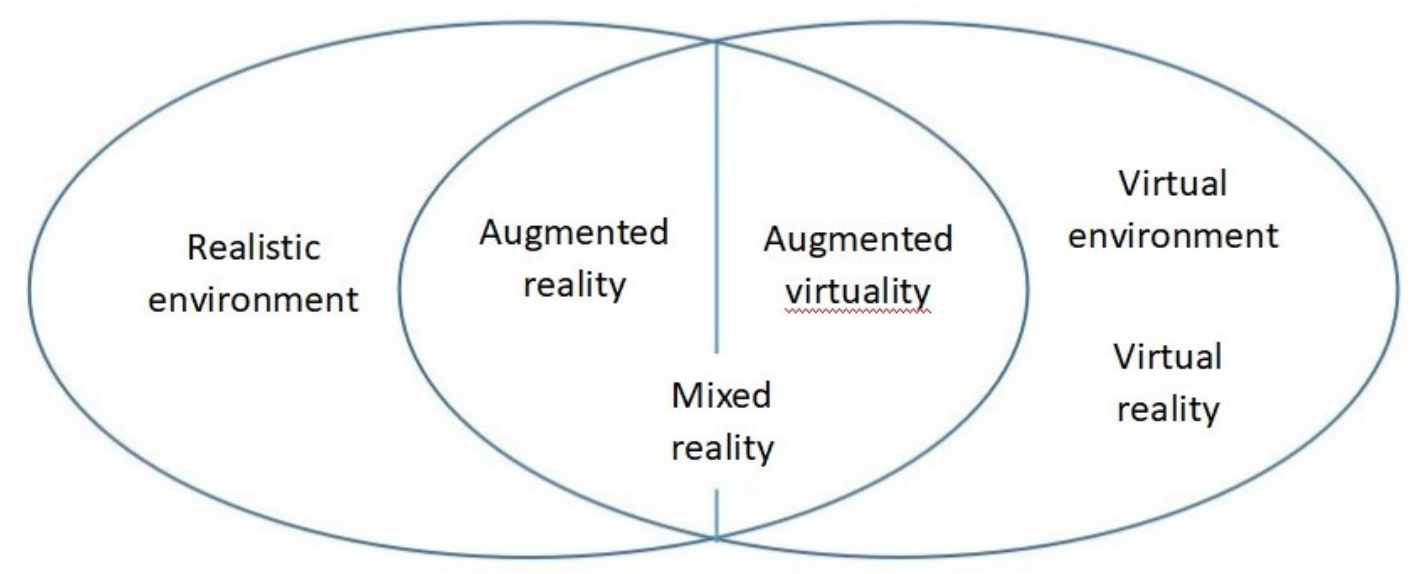

Figure 1: Relationship of VR, AR and MR

\section{Resource integration of VR / AR technology and primary school science}

\subsection{Introduction of VR / AR related software}

It is divided into two categories to introduce the following ten softwares and their functions and Applications (as shown in Table 1).

Table 1: Introduction of VR / AR related software

\begin{tabular}{|c|c|c|}
\hline Classification & Software Name & Function and Application \\
\hline \multirow{4}{*}{ VR software } & $\begin{array}{c}\text { Judao 3D } \\
\text { Laboratory of } \\
\text { primary school } \\
\text { science }\end{array}$ & $\begin{array}{l}\text { It includes six modules: scientific } 3 \mathrm{D} \\
\text { synchronous experiment, scientific } \\
\text { exploration platform · electricity, scientific 3D } \\
\text { exploration platform · optics, life world, } \\
\text { scientific experimental equipment library and } \\
\text { geographic encyclopedia. It can be operated and } \\
\text { observed directly. }\end{array}$ \\
\hline & $\begin{array}{l}\text { Judao life science } \\
\text { 3D interactive } \\
\text { teaching software }\end{array}$ & $\begin{array}{l}\text { It includes three modules: human body } \\
\text { exploration, evolutionary tree and endless life. It } \\
\text { can learn all kinds of human systems and } \\
\text { organs, understand all kinds of animals, plants, } \\
\text { microorganisms and gene related knowledge. }\end{array}$ \\
\hline & NOBOOK & $\begin{array}{l}\text { It can be divided into courseware resources, } \\
\text { observation experiments and hands-on } \\
\text { experiments, including material science, life } \\
\text { science, earth and universe science and } \\
\text { technology and engineering. Teachers can } \\
\text { publish their own courseware or modify the } \\
\text { original courseware on the platform. }\end{array}$ \\
\hline & $\begin{array}{l}\text { Exploring the } \\
\text { human body } \\
\text { (Mobile app) }\end{array}$ & $\begin{array}{l}\text { It includes eight modules of nervous system, } \\
\text { skeletal system, respiratory system, circulatory } \\
\text { system, digestive system, muscle system, } \\
\text { immune system and skin system, as well as }\end{array}$ \\
\hline
\end{tabular}




\begin{tabular}{|c|c|c|}
\hline & & $\begin{array}{l}\text { various organs in each system. It is equipped } \\
\text { with sound and explanation, and can be operated } \\
\text { by hands. }\end{array}$ \\
\hline & Solar Walk & $\begin{array}{l}\text { It can be used to observe planets, satellites and } \\
\text { celestial bodies. It can enlarge, shrink and rotate, } \\
\text { and then observe more deeply from multiple } \\
\text { angles. }\end{array}$ \\
\hline \multirow{5}{*}{ AR software } & $\begin{array}{c}\text { Plantale }^{[6]} \\
\text { (Mobile app) }\end{array}$ & $\begin{array}{l}\text { It includes germination, reproduction, plants } \\
\text { under AR and activity. It can directly observe } \\
\text { the various structures of plants and the whole } \\
\text { process of plant growth. }\end{array}$ \\
\hline & $\begin{array}{l}\text { Froggipedia } \\
\text { (Mobile app) }\end{array}$ & $\begin{array}{l}\text { It can learn the life cycle of frogs, conduct AR } \\
\text { anatomy of frogs, and then observe the } \\
\text { morphology of various organs of frogs more } \\
\text { intuitively and clearly, and learn the functions of } \\
\text { various organs. }\end{array}$ \\
\hline & Z Space & $\begin{array}{l}\mathrm{Z} \text { space has developed the courseware of } \\
\text { multiple subjects for grade } 2-12^{[7]} \text {. Steam } \\
\text { laboratory courseware is widely used in the } \\
\text { United States, including science, mathematics, } \\
\text { technology, engineering and other courses. }\end{array}$ \\
\hline & Metaio & $\begin{array}{l}\text { The application of AR education based on } \\
\text { location-based service is helpful for students to } \\
\text { be familiar with the location and understand the } \\
\text { campus and campus culture. }\end{array}$ \\
\hline & $\begin{array}{l}\text { ENTiTi } \\
\text { Creator }\end{array}$ & $\begin{array}{l}\text { Easy to learn, just drag and drop the mouse to } \\
\text { complete the creation. It can automatically adapt } \\
\text { to a variety of terminals, such as mobile phone } \\
\text { or platform computer, Samsung gear VR box, } \\
\text { Vuzix smart glasses, etc. }{ }^{[8]} \text {. }\end{array}$ \\
\hline
\end{tabular}

\subsection{Lesson analysis}

Taking Our Respiratory Organs as an example, Momdao life science VR and 3D interactive teaching software were used to integrate teaching resources.

This lesson is mainly to identify the various respiratory organs of the human body and the path of gas inhalation and exhalation, and understand the structure and function of human respiratory organs, which can be divided into four parts: first, find problems from the familiar breathing situation, and arouse students' thinking. Then, according to students' thinking and conjecture, introduce each respiratory organ and its function in turn. After that, after students understand each respiratory organ On the basis of respiratory organs, the scattered respiratory organs are put together to make the students further understand the distribution position of each respiratory organ in the body and strengthen their memory. Finally, after the students understand each respiratory organ, the distribution position of each respiratory organ in the body is made clear, and the respiratory organs are connected together to form a whole by the flow path of gas when we breathe .So that students can better understand the breathing of human body.

The second step is to understand the respiratory organs. The textbook only shows a picture of human respiratory organs, which can only enable students to understand the various respiratory 
organs of the human body from the surface according to the shape of the picture. However, it is difficult for students to understand the internal structure of respiratory organs through simple explanation, especially for the understanding of the gas exchange in the alveoli at the end of bronchus.Therefore, it can be explained by combining with the moment life science VR and 3D interactive teaching software. The 3D model of the respiratory system can be displayed through the software. Students can learn the respiratory organs such as nose, pharynx, larynx, trachea, bronchus and lung as a whole (as shown in Figure 2), and they can also split each expiratory organ to learn one by one (as shown in Figure 3). In addition, each respiratory organ has a corresponding annotation to help students understand. Students can rotate the 3D model of the respiratory system on the whiteboard by fingers or mouse, so as to observe the characteristics of each respiratory organ more intuitively. In addition, you can also click the lung to enter the learning of alveoli (as shown in Figure 4). Combined with the alveoli, you can explain the process of gas exchange for students, and learn more about the internal structure of the lung. In addition, click the play option to demonstrate the animation of human breathing, which can not only make students study intuitively, but also attract students' attention.

Combined with VR /AR software for primary school science teaching, students are not simply listening to the teacher's explanation, but through more intuitive visual impact, more real hands-on operation, wholeheartedly into the whole process of teaching. The integration of teaching resources, the guidance of teachers and the active participation of students make the teaching effect get twice the result with half the effort.

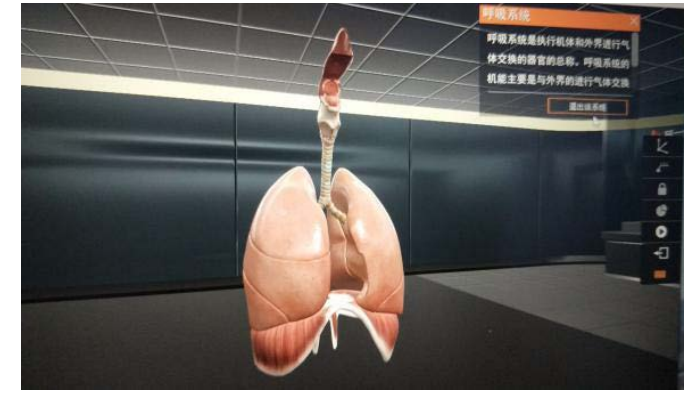

Figure 2: Overall view of lung model

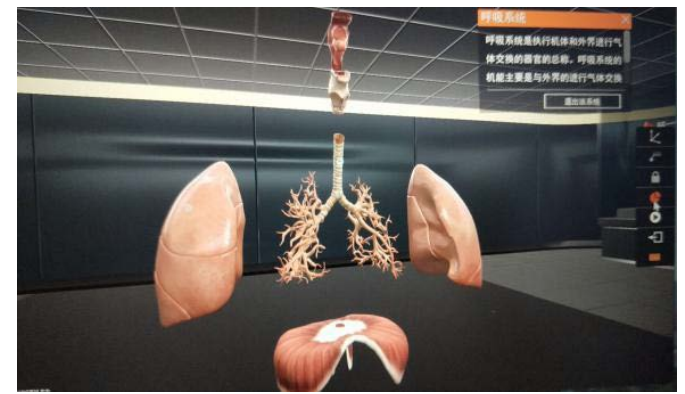

Figure 3: Split lung model

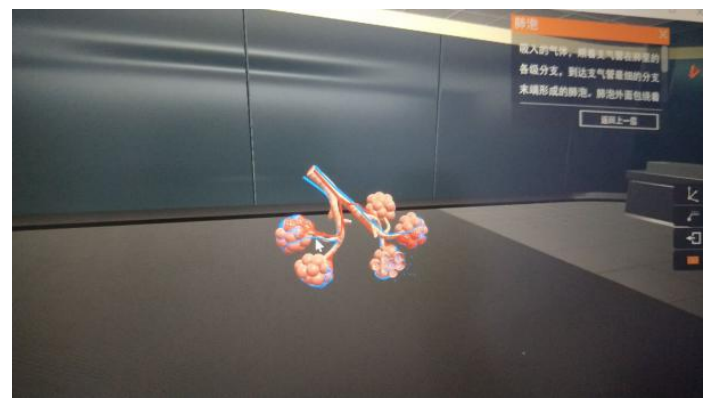

Figure 4: Alveolar model

\section{Advantages of resource integration of VR technology and primary school science}

\subsection{Abstract content visualization, improve learning effect}

In primary school science teaching, there are many contents that are difficult to explain clearly in words, and for primary school students, their understanding ability is not strong, especially difficult to understand abstract and complex problems. Therefore, teachers need to update the original teaching methods and means, develop relevant teaching resources, and VR technology can show its 
advantages. Through VR related software or equipment, students can observe 3D models from a variety of perspectives, visualize and visualize the abstract and difficult to understand learning content, so as to improve students' learning effect.

\subsection{Immersive interactive experience to improve learning interest}

The traditional classroom is basically through the teacher's explanation to carry out teaching activities, in this kind of classroom, students' attention duration is short, learning interest is not high, so the knowledge they learned is not deep memory, learning efficiency is low. VR technology has a variety of sensory effects, especially can create a sense of immersion in the environment of learners, and support the natural interaction between learners and virtual objects in the virtual / real environment. This can realize the interaction between learners and objects, realize personalized learning, improve the concentration, participation and interest of learning, and enable students to cross the boundaries of time and space, such as traveling freely in the sea of books, so that the content in books can be touched, interacted and perceived ${ }^{[9]}$.

\subsection{Cost saving and equity of educational resources}

In primary school science teaching, we need certain learning places and experimental equipment, but for some rural primary schools, it can not meet the requirements of soft and hard facilities for science learning. However, through the use of VRtechnology related software, the integration of teaching resources, can reduce the cost of teaching, so that students in less developed areas can also do a good job in primary school science learning, which is conducive to the fairness and balance of educational resources.

\section{Summary}

With the rapid development of science and information technology, while bringing convenience to people's lives, it is also necessary to integrate it with educational resources to make education easier to carry out and achieve better educational effect. Virtual and augmented reality technology has developed rapidly in recent years, which can bring great convenience to education. As a comprehensive discipline, primary school science needs the integration of these advanced technologies.

\section{Acknowledgment}

This work was sponsored by the 2020 Normal Education Curriculum Reform Research Project of Zhengzhou Normal University: The Research on the Interdisciplinary Teaching Quality of Normal University Students Based on Project Learning (JSJY-20937).

\section{References}

[1] Zhao Fujun, Li Yuying. Comparative analysis of old and new curriculum standards for primary school science [J]. Journal of Corps College of Education,2018,28(03):72-76

[2] Fan Jing. Current Situation and Influencing Factors of Science Teaching in Primary Schools [J]. Contemporary Family Education, 2020(26):144-145.

[3] Wang Tongjun. Virtual and Augmented Reality (VR/AR) Technology in Teaching Application and Prospect [J]. Digital Education, 2017,3(01):1-10.

[4] Liu C S. Application of augmented reality technology (AR) in biology teaching [J]. Biology of High School, 2020, 36(07):63-65.

[5] Gao Qi. Research on the Design and Practice of Primary Science Learning Activities Based on AR from the 
Perspective of Deep Learning [D]. Shaanxi Normal University, 2019.

[6] Wang Shujia, Liu Kaiyu. The application of augmented reality technology (AR) in biology teaching in middle school [J]. Biology Teaching, 2020, 45(01):39-40.

[7] Cai Su, Wang Peiwen, Yang Yang, Liu Enrui. A review of augmented reality (AR) technology in education [J]. Journal of Distance Education, 2016, 34(05):27-40.

[8] Zhou Sen, Yin Bangman. Augmented reality technology and its application status and development opportunities in the field of education [J]. Electronic Education Research, 2017, 38(03):86-93.

[9] Li Rui. Research on the Application of Augmented Reality Technology in Teaching [J]. Joint Journal of Tianjin Vocational Colleges, 2020, 22(09):65-68. 